\title{
RELICTOS DEL PAISAJE HISTORICO RURAL DE URUGUAY: ESTRUCTURAS EN PIEDRA RELEVADAS EN ESTUDIOS DE IMPACTO ARQUEOLOGICO
}

Irina Capdepont Caffa ${ }^{1}$

\section{RESUMEN}

En este trabajo se presentan las evidencias materiales del paisaje rural de diferentes zonas de Uruguay. El registro material refiere a estructuras en piedra relevadas en estudios de evaluación y diagnostico de impacto arqueológico. Buscando ahondar en el conocimiento de los paisajes antrópicos de Uruguay, se da continuidad a estos estudios de impacto. Entendiendo esta continuidad como parte de la mitigación del impacto, se presentan cinco casos de estudio que evidencian procesos de ocupación y explotación del medio rural a partir del siglo XVII. Las estructuras en piedra identificadas como mangueras, corrales, muros y hornos, entre otros, forman parte del testimonio del pasado histórico del territorio. Este tipo de testimonio se relaciona con prácticas sociales articuladas a un sistema tradicional de uso de la tierra y sus recursos.

Palabras clave: Paisaje rural; estructuras en piedra

\section{RESUMO}

Neste trabalho, apresentam-se as evidências materiais da modificação da paisagem rural em diferentes zonas do Uruguai. O registro material corresponde a estruturas em pedra relevadas em estudos de avaliação e diagnóstico de impacto arqueológico. Procurando aprofundar o conhecimento das paisagens antrópicas do Uruguai, propõe-se que a continuidade destes projetos é crucial para os estudos arqueológicos e a mitigação do impacto. Aqui apresentam-se cinco estudos de caso que evidenciam processos de ocupação e exploração que tiveram lugar no meio rural a partir do século XVII. As estruturas em pedra identificadas como mangueiras, canetas, paredes e fornos, entre outros, são parte do testemunho do passado histórico do território. Este tipo de testemunho patrimonial está relacionado com um conjunto de práticas sociais articuladas a um sistema tradicional de uso da terra.

Palavras-chave: Paisagem rural; estruturas em pedra.

\section{ABSTRACT}

This paper presents the material evidence of the rural landscape modification in different areas of Uruguay. The material record includes stone structures such as corrals and walls detected during surveys carried out during archaeological impact assessment. In order to deepen knowledge about the anthropic landscape of Uruguay we propose that project continuity is crucial to both archaeological studies and impact mitigation. Here, we present

1 Laboratorio de Estudios del Cuaternario (UNCIEP-IECA, Facultad de Ciencias-Ministerio de Educación y Cultura) iracap@yahoo.com.ar 


\section{Revista de Arqueologia Pública}

five case studies showing occupation and exploitation processes carried out in the rural areas since S. XVIII. The stone structures identified as hoses, corrals, walls and ovens, are part of the historical past of the territory. Finally, we relate this patrimony with a set of social practices deeply interwoven in a traditional land-use system.

Keywords: Rural landscape; structures in stone

\section{Introducción}

El desarrollo económico y los procesos de modernización generan transformaciones significativas en el paisaje. El acelerado proceso de ocupación del suelo, especialmente para usos industriales, como el caso de represas hidroeléctricas, canteras, parques eólicos y fábricas de celulosa, entre otras, cambian la fisonomía de los paisajes característicos del territorio, alterando paisajes antrópicos históricos y prehistóricos. Ejemplo de ello es la represa hidroeléctrica de Salto Grande, que en la década del 1970 impactó de forma critica el paisaje, generándose importantes pérdidas de secuencia sociocultural de ocupaciones humanas prehistóricas y proto-históricas que ocuparon el litoral del río Uruguay. Entrado el siglo XXI, otros grandes emprendimientos (forestación, urbanización, actividades agrícolaganaderas y la extranjerización de la tierra, entre otros) generan impactos importantes sobre el medio y el registro arqueológico. Registro que forma parte del patrimonio cultural y que de acuerdo a su carácter de bien de interés público, frágil y no renovable, se encuentra amparado, entre otras, en la Ley de Impacto Ambiental (№ 16.466-Decreto 435/994). Esta ley exige, a los diferentes emprendimientos, la realización de la evaluación y diagnostico de impacto arqueológico. En este marco legal se han llevado a cabo, en distintas zonas del país, estudios de impacto (EIArq) que evidencian distintos tipos de paisajes antrópicos.

En el presente trabajo se exponen los datos obtenidos del relevamiento de restos materiales, memoria del paisaje histórico, identificados en cinco EIARq. El trabajo se centra en las evidencias materiales de ocupaciones humanas históricas representadas por distintas estructuras en piedra. Con estos estudios se busca ahondar en el conocimiento de los paisajes antrópicos, así como en los procesos de ocupación y explotación que se dieron en el medio. La proyección de canteras y fábricas en tres departamentos del país (Figura 1 y Tabla 1), constituyó el marco para conjugar el estudio de impacto como iniciativa de investigación del paisaje rural, generación de conocimiento y divulgación. Entre los objetivos planteados se encuentran: a. registrar los restos culturales relacionados con estructuras en piedra en las diferentes unidades del paisaje; b. procesar los datos con herramientas GIS; c. 


\section{Revista de Arqueologia Pública}

obtener como producto final un inventario de los restos culturales y $d$. proponer criterios y medidas para la protección y conservación de los restos que forman parte del patrimonio cultural rural del territorio.

Las estructuras en piedra se hallan dispersas por todo el territorio, formando parte del paisaje cultural histórico del territorio. Las estructuras que se presentan en esta instancia se asocian al manejo pecuario originario del territorio, así como también evidencian el aprovechamiento de los recursos que brinda el medio. En las regiones del país donde la piedra se encuentra inmediatamente disponible, se releva, para períodos históricos, su uso como material constructivo en mangueras o cercos, corrales, hornos de cal, cascos y puestos de estancia, entre otros. Estas estructuras son registro del paisaje rural, registro que ha sido abordado a partir de documentación histórica (e.g. BARRIOS PINTOS, 1962, 1967; 1969; BARRAN, 1974; NAHUM 1997), cartografía topográfica del Servicio Geográfico Militar y estudios de impacto arqueológico (e.g. CAPDEPOTN y DEL PUERTO, 2013, 2014; CASTIÑEIRA et al., 2006; DEL PUERTO y CAPDEPONT, 2012; FLORINES et al., 2011).

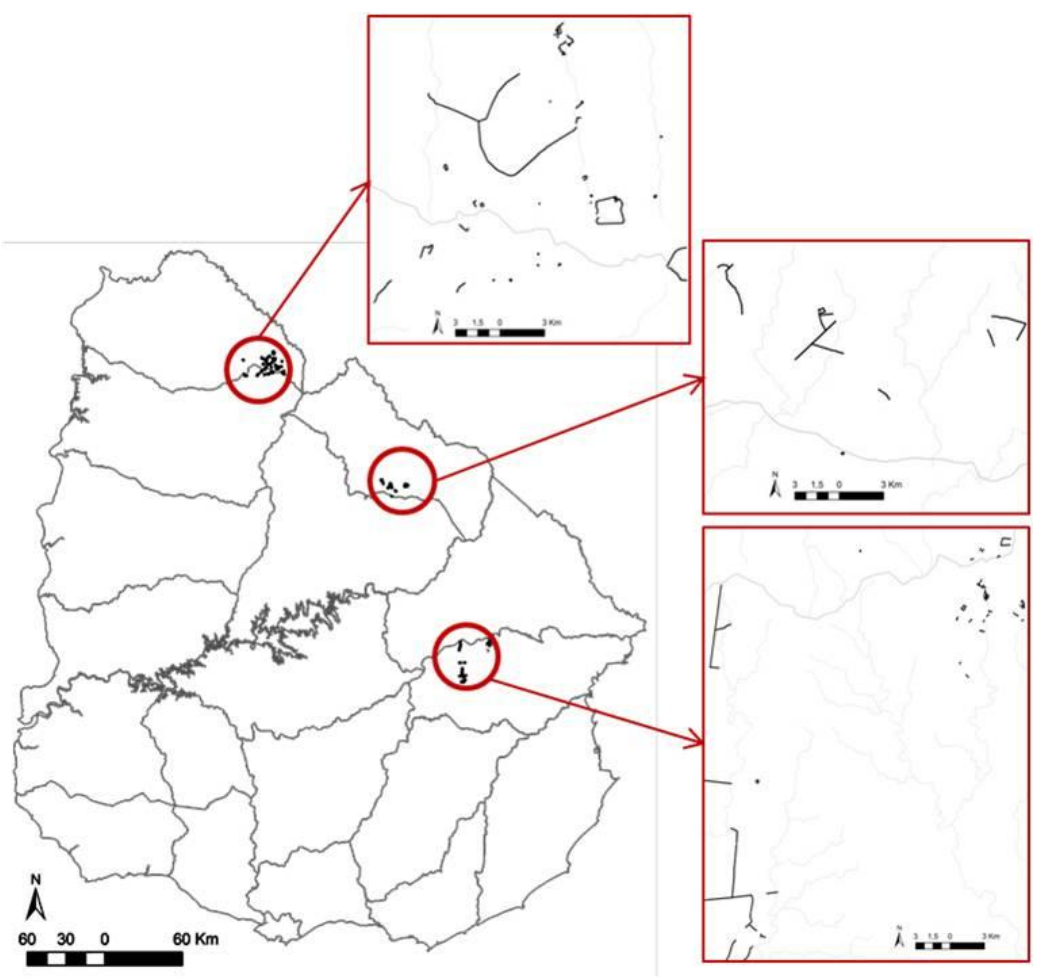

Figura 1. Ubicación de las estructuras en piedra en cartas topográficas del Servicio Geográfico Militar (escala 1:50.000) de los sectores abordados en los departamentos Artigas (carta K7), Rivera (carta G12) y Treinta y Tres (cartas E18-E19). 


\section{Revista de Arqueologia Pública}

\begin{tabular}{|c|c|c|c|c|c|}
\hline Departamento & № Padrón & Emprendimiento & Acción & Afección & $\begin{array}{l}\text { Tipo de } \\
\text { registro }\end{array}$ \\
\hline \multirow{3}{*}{ Treinta y Tres } & 816 y 1213 & $\begin{array}{c}\text { Planta de Clinker } \\
\text { y cemento } \\
\text { Portland }\end{array}$ & $\begin{array}{l}\text { Desmalezamiento, } \\
\text { excavaciones, tránsito } \\
\text { maquinaria y } \\
\text { edificación. }\end{array}$ & \multirow{5}{*}{$\begin{array}{l}\text { Remoción } \\
\text { suelo y } \\
\text { subsuelo }\end{array}$} & \multirow[t]{2}{*}{$\begin{array}{l}\text { Corral } \\
\text { Manguera } \\
\text { Casco de } \\
\text { estancia }\end{array}$} \\
\hline & $\begin{array}{l}9490,9491 y \\
9492\end{array}$ & \multirow{2}{*}{$\begin{array}{c}\text { Explotación } \\
\text { minera de piedra } \\
\text { caliza }\end{array}$} & \multirow{2}{*}{$\begin{array}{l}\text { Extracción con } \\
\text { explosivos y } \\
\text { retroexcavadora }\end{array}$} & & \\
\hline & $\begin{array}{l}3072,3184, \\
5446 \text { у } 8363\end{array}$ & & & & $\begin{array}{l}\text { Hornos de } \\
\text { Cal }\end{array}$ \\
\hline Rivera & $\begin{array}{l}2448,3687 \\
8625,8510 \\
9402,5331 y \\
8758\end{array}$ & $\begin{array}{l}\text { Explotación de } \\
\text { mineral aurífero }\end{array}$ & $\begin{array}{l}\text { Extracción con } \\
\text { explosivos y } \\
\text { retroexcavadora }\end{array}$ & & $\begin{array}{c}\text { Corral } \\
\text { Manguera } \\
\text { Habitaciones }\end{array}$ \\
\hline Artigas & 5375 & $\begin{array}{c}\text { Explotación } \\
\text { minera de ágatas } \\
\text { y amatistas }\end{array}$ & $\begin{array}{l}\text { Pala frontal y } \\
\text { retroexcavadora }\end{array}$ & & $\begin{array}{l}\text { Posta de } \\
\text { diligencias }\end{array}$ \\
\hline
\end{tabular}

Tabla 1. Síntesis de los emprendimientos realizados en los sectores de los departamentos involucrados en este estudio y tipo de registro relevado durante actividades de prospección.

\section{Estrategia de investigación}

El trabajo arqueológico desarrollado en los EIARq de emprendimientos mineros, siguió la estrategia expuesta a continuación. Para su diseño se consideraron los supuestos teóricosmetodológicos referidos en AMADO et al. (2002); AMADO y BARREIRO (2007); BARREIRO (2002) y CRIADO et al. (2000) y sintetizados a continuación.

1. Relevamiento de Antecedentes e Identificación de afecciones. Se realizó, como primer paso metodológico-técnico, el estudio de los antecedentes documentales de investigaciones arqueológicas desarrolladas en el área a ser afectada por el emprendimiento. Ello implicó el relevamiento de antecedentes (históricos, patrimoniales, geológicos, geográficos, entre otros) para diseñar el trabajo de campo y contextualizar los resultados obtenidos. A partir de los antecedentes y los planes de obra proyectados por la empresa concesionaria, se llevó a cabo la identificación de las posibles afecciones sobre eventuales entidades arqueológicas. 


\section{Revista de Arqueologia Pública}

2. Prospección Arqueológica. A partir del análisis de antecedentes, se implementó un diseño de prospección pedestre, mediante el cual se pretendió acceder a una determinada muestra de evidencias naturales y/o culturales de interés arqueológico, dentro de un campo de análisis hasta entonces no caracterizado. Para la realización de la prospección se contó con un plan que abarcó dos instancias diferentes tomando en cuenta los procedimientos sugeridos por el Departamento de Arqueología de la Comisión del Patrimonio Cultural de la Nación (CPCN-MEC).

A. Prospección superficial: Se llevó a cabo una prospección superficial sistemática pedestre. En forma simultánea, la prospección sistemática se complementó con una prospección dirigida, apuntando a reconocer estructuras específicas. Con esto se atendió a zonas de mayor visibilidad (afloramientos, barrancas, cauces, trillos, suelo denudado, etc.) o zonas puntuales, previamente abordadas por fotointerpretación.

B. Prospección subsuperficial: Las tareas de relevamiento superficial se complementaron con intervenciones arqueológicas puntuales, con el objetivo de indagar el subsuelo en zonas de baja visibilidad arqueológica. Ello apuntó a detectar la existencia de materiales arqueológicos en estratos sub-superficiales. El acceso al subsuelo se realizó manualmente utilizando pala recta, cucharín y espátula. La identificación de todos los puntos relevados, superficiales y sub-superficiales, se realizó con el apoyo de tecnología GPS.

3. Evaluación y Diagnóstico. Buscando evitar o mitigar la generación del impacto a ser producido por las obras proyectadas sobre el registro material, se propusieron medidas de corrección compensatorias (documentación, delimitación y difusión) estableciendo puntos de interés y potencial arqueológico. Mediante la integración en un Sistema de Información Geográfica (SIG) de todos los datos relevados en las etapas precedentes, se define y caracteriza el área estudiada, evaluando los efectos del impacto. Dependiendo del efecto, así como de la magnitud e incidencia de las obras proyectadas, se definen los siguientes tipos de impacto:

-Crítico: es la afección más grave (desaparición parcial o total del registro), implica la adopción de medidas correctoras destinadas a evitar el impacto: modificación del diseño del proyecto y/o aplicación de medidas compensatorias como investigación arqueológica. 


\section{Revista de Arqueologia Pública}

-Severo: puede ser mitigado en fase de ejecución de la obra, adoptando medidas preventivas (controles) y paliativas (documentación exhaustiva, caracterización y protección preventiva).

-Moderado: riesgo de afección relativo que podría ser producto de una afección visual.

-Compatible: inexistencia de riesgo de afección.

\section{Resultados}

Las estructuras en piedra ubicadas en diferentes unidades del paisaje, no documentadas con anterioridad, fueron relevadas en instancias de prospección, mediante fichas de registro. Para los cinco casos de estudio, fue necesario proponer entornos de protección de las estructuras. Ello responde a que las actividades proyectadas en los distintos emprendimientos afectarían estas estructuras. Los impactos a ser producidos por las obras se consideran compatibles con la conservación del patrimonio arqueológico, en la medida en que se lleven a cabo las medidas preventivas necesarias, como ser la delimitación de zonas de exclusión. Considerando los distintos niveles de impacto potenciales, de acuerdo a la intensidad de la alteración y a la certeza o riesgo de que esta se produzca efectivamente, se definen entornos de protección de al menos 10 metros de diámetro, donde no deberán realizarse actividades de obra. Ello se justifica para todos los casos de estudio dado que las acciones proyectadas involucran movimientos de suelo con empleo de maquinaria pesada de alto impacto. Son las etapas de nivelación del terreno y terraplenado las de mayor impacto potencial sobre el área. En este contexto, se presentan a continuación, en forma de síntesis, los antecedentes, las características del paisaje y los principales resultados obtenidos en los estudios realizados en los distintos sectores a ser afectados por las obras.

Treinta y Tres

A nivel general, el departamento presenta diversos tipos de sitios arqueológicos históricos y prehistóricos. PRIETO et al. (1970) y CABRERA y MAROZZI (2001) ubican y describen sitios estratificados, sitios en superficie y sitios con estructuras monticulares (cerritos de indios). Asimismo, FEMENÍAS (1983) y BARRIOS PINTOS (1973) hacen 


\section{Revista de Arqueologia Pública}

mención a estructuras de piedra conocidas como cairnes, vichaderos, conos o chenques, ubicadas en la cima de cerros, vinculándolas con actividades rituales o prácticas fúnebres de los indígenas, así como a lugares de guardia y estructuras para señales de humo.

En el marco de estudios de impacto arqueológico en áreas a ser afectadas por emprendimientos económicos (CAPDEPONT et al., 2004; INDA, 2005; DEL PUERTO y CAPDEPONT, 2012, entre otros) se han relevado escasos materiales culturales prehistóricos. En contraposición, estos estudios han evidenciado numerosos registros de la actividad industrial histórica (hornos de cal) y la vida rural del período comprendido entre los siglos XVIII y XIX.

Las estructuras identificadas en el departamento, constituyen relictos de estructuras mayores hoy inexistentes. La construcción y operación de una planta de fabricación de clinker, cemento portland y materiales afines, proyectada sobre un área de 46,7 hectáreas en sectores de los padrones № 816 y No 1213, implicó la realización de un EIArq. El área afectada por el proyecto comprende sierras rocosas, afloramientos y suelos superficiales en los que se desarrolla la pradera (MGAP, 2001). Para el área de trabajo fueron relevadas cinco estructuras en piedra (Est.01 a Est.05), cuyas características se exponen en la Tabla 2 (Figura 2 y Figura 3).

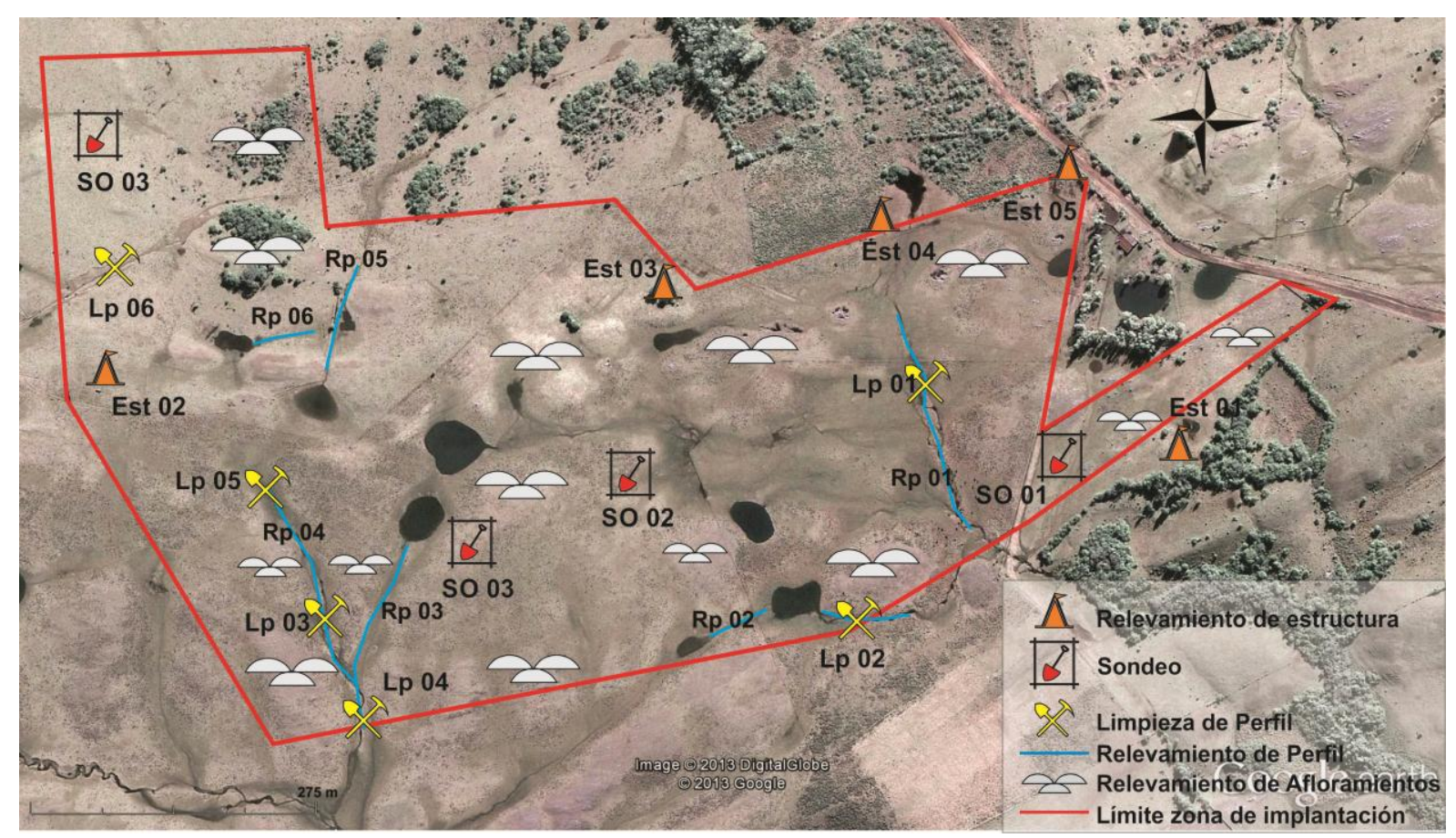

Figura 2. Delimitación del área de obra, distribución de las estructuras y actividades realizadas en fase de prospección en base a imagen Satelital Google Earth (Fuente: CAPDEPONT y DEL PUERTO, 2013:41). 


\section{Revista de Arqueologia Pública}

\begin{tabular}{|c|c|c|}
\hline Identificador & Coordenadas & Características de estructuras \\
\hline Est. 01 & $\begin{array}{l}\text { S. } 32^{\circ} 50^{\prime} 39.65^{\prime \prime} \\
0.54^{\circ} 23^{\prime} 45.53^{\prime \prime}\end{array}$ & $\begin{array}{l}\text { Aunque se encuentra fuera del área del proyecto, se releva una } \\
\text { estructura compleja, construida con lajas de roca caliza } \\
\text { colocadas verticalmente. Las mismas modelan paredes rectas } \\
\text { de } 1,50 \mathrm{~m} \text { y } 0,50 \mathrm{~m} \text { de altura, dispuestas tanto en forma lineal, } \\
\text { como formando encierros circulares y cuadrangulares con } \\
\text { corredores internos. La estructura corresponde a un antiguo } \\
\text { corral con distintas mangas. }\end{array}$ \\
\hline Est.02 & $\begin{array}{l}\text { S. } 32^{\circ} 50^{\prime} 36.90^{\prime \prime} \\
\text { O. } 54^{\circ} 24^{\prime} 26.32^{\prime \prime}\end{array}$ & $\begin{array}{l}\text { Fragmento relictual de un antiguo cerco lineal, integrado por } \\
\text { fragmentos de rocas caliza dispuestas horizontalmente. El cerco } \\
\text { presenta } 1,30 \mathrm{~m} \text { de altura y } 1 \mathrm{~m} \text { de ancho y se extiende a lo } \\
\text { largo de } 5 \mathrm{~m} \text {, continuándose hacia el oeste del área en estudio. }\end{array}$ \\
\hline Est. 03 & $\begin{array}{l}\text { S. } 32^{\circ} 50^{\prime} 34.06^{\prime \prime} \\
\text { O. } 54^{\circ} 24^{\prime} 5.33^{\prime \prime}\end{array}$ & $\begin{array}{l}\text { Restos de una construcción lineal, de } 20 \text { m de largo, conformada } \\
\text { por lajas de roca caliza. Su disposición genera paredes rectas de } \\
0,70 \mathrm{~m} \text { de altura y } 0,90 \text { m de ancho. Se trata de parte de un cerco } \\
\text { o manguera construido con lajas cortas (de entre } 20 \text { a } 40 \mathrm{~cm} \text { ) } \\
\text { dispuestas en forma vertical y encastradas unas a otras. }\end{array}$ \\
\hline Est. 04 & $\begin{array}{l}\text { S. } 32^{\circ} 50^{\prime} 32.29^{\prime \prime} \\
\text { O.54 } 24^{\circ} 23^{\prime} 56^{\prime \prime}\end{array}$ & $\begin{array}{l}\text { Se trata de parte de una estructura lineal construida con roca } \\
\text { caliza canteada de } 1,50 \mathrm{~m} \text { de largo y } 0,60 \mathrm{~m}-0,70 \mathrm{~m} \text { de altura. La } \\
\text { construcción formada por medio de la superposición de las rocas } \\
\text { refiere a parte de una manguera de } 350 \mathrm{~m} \text { de largo. }\end{array}$ \\
\hline Est. 05 & $\begin{array}{l}\text { S. } 32^{\circ} 50^{\prime} 30.96 " \\
\text { O. } 54^{\circ} 23^{\prime} 49.43^{\prime \prime}\end{array}$ & $\begin{array}{l}\text { Relicto de estructura en piedra que conforma un cerco. El mismo } \\
\text { ha sido construido con roca caliza. Las paredes del cerco } \\
\text { presentan un alto que va entre } 0,70-0,60 \mathrm{~m} \text { y un ancho de } 0,50 \\
\mathrm{~m} \text {. }\end{array}$ \\
\hline
\end{tabular}

Tabla 2. Síntesis de las características de las estructuras en piedra relevadas en prospección. 

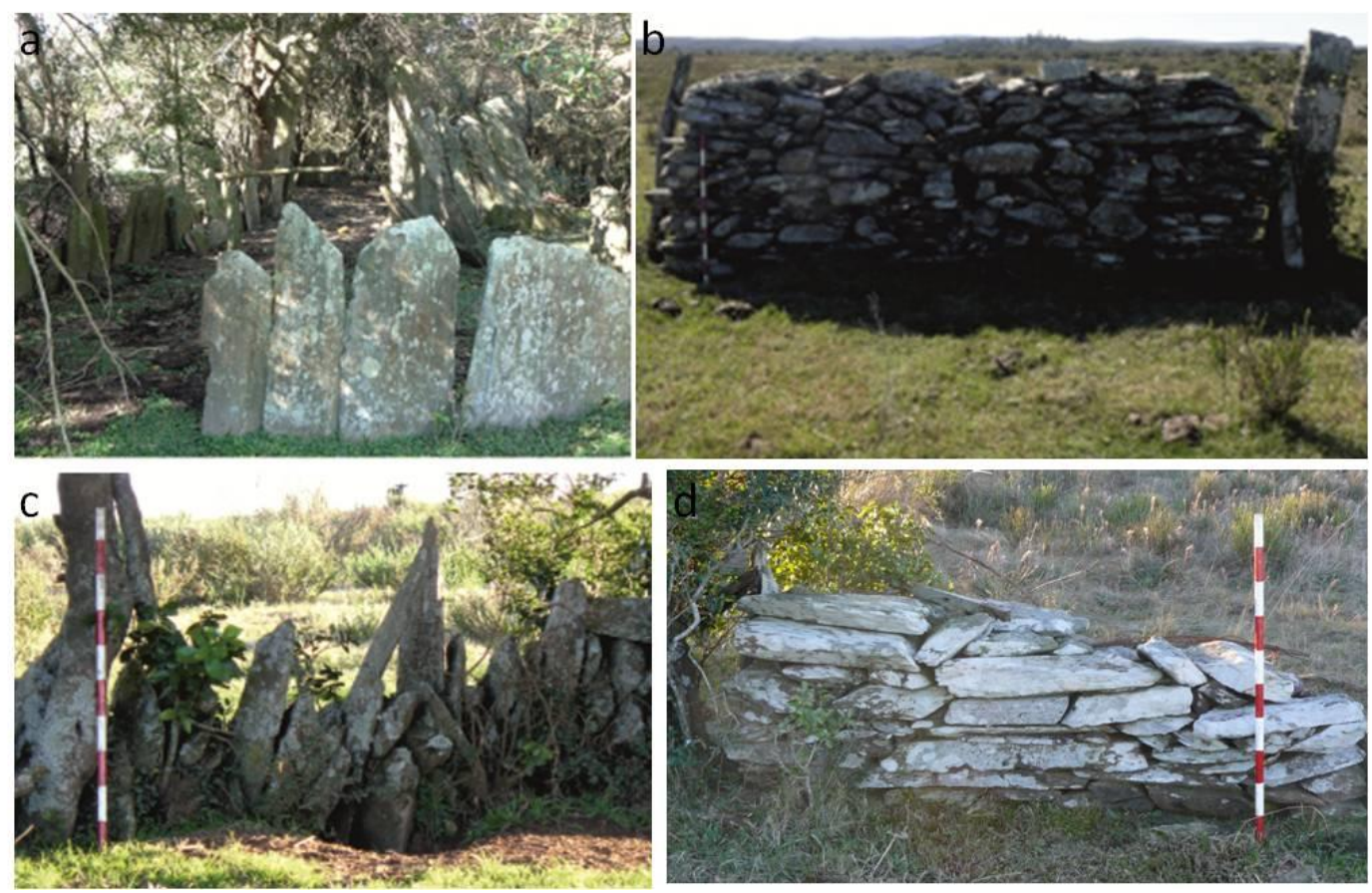

Figura 3. Representación de las estructuras en piedra del área: a. Est. 01; b. Est. 02; c. Est. 03 y d. Est. 04 (Fuente: CAPDEPONT y DEL PUERTO, 2013).

En el marco del proyecto de explotación minera de roca caliza, ubicado en sectores de los padrones № 9490, 9491 y 9492, fueron registradas siete estructuras en piedra (Tabla 3) emplazadas en la misma zona geológica y geomorfológica que el emprendimiento mencionado en los párrafos anteriores (Figura 4 y Figura 5).

\begin{tabular}{|c|c|c|}
\hline Identificador & Coordenadas & Características de estructuras \\
\hline Est. 01 & $\begin{array}{l}\text { S. } 32^{\circ} 49^{\prime} 57.34^{\prime \prime} \\
\text { O.54²6'33.97" }\end{array}$ & $\begin{array}{l}\text { Estructura ubicada fuera del límite del pedimento y asociada a } \\
\text { un conjunto de otras estructuras en piedra de roca caliza } \\
\text { relacionadas con un espacio habitacional. Espacio en el que } \\
\text { además de vivir, se llevaron y llevan a cabo actividades rurales } \\
\text { desde el siglo XVII. }\end{array}$ \\
\hline Est.02 & $\begin{array}{l}\text { S. } 32^{\circ} 49^{\prime} 56.69^{\prime \prime} \\
\text { O.54 } 54^{\circ} 26^{\prime} 31.28^{\prime \prime}\end{array}$ & $\begin{array}{l}\text { Se trata de una estructura en piedra, de forma rectangular, con } \\
\text { alturas que varían de } 1,30 \text { a } 1,50 \mathrm{~m} \text {. La estructura ha sido } \\
\text { identificada como corral y se la relaciona a la Est. } 01 \text {. }\end{array}$ \\
\hline Est. 03 & $\begin{array}{l}\text { S. } 32^{\circ} 49^{\prime} 56.57^{\prime \prime} \\
\text { O. } 54^{\circ} 26^{\prime} 9.33^{\prime \prime}\end{array}$ & $\begin{array}{l}\text { Relicto de una manguera de } 0,30 \text { a } 0,50 \mathrm{~m} \text { de altura, conformada } \\
\text { por lajas insertas verticalmente. Se extiende unos } 1000 \mathrm{~m} \text {. } \\
\text { lineales. }\end{array}$ \\
\hline Est. 04 & $\begin{array}{l}\text { S. } 32^{\circ} 49^{\prime} 33.55^{\prime \prime} \\
\text { O. } 54^{\circ} 25^{\prime} 44.82^{\prime \prime}\end{array}$ & $\begin{array}{l}\text { Restos de manguera formada por lajas de roca caliza que se } \\
\text { encuentran dispuestas en forma vertical. La misma es visible en } \\
450 \mathrm{~m} \text {. de longitud. }\end{array}$ \\
\hline & Pública & \begin{tabular}{l|l|} 
Campinas, SP & v. 10
\end{tabular} \\
\hline
\end{tabular}


Revista de Arqueologia Pública

\begin{tabular}{|c|l|l|}
\hline Est. 05 & $\begin{array}{c}\text { S. } 32^{\circ} 49^{\prime} 21.92^{\prime \prime} \\
0.54^{\circ} 26^{\prime} 28.91^{\prime \prime}\end{array}$ & $\begin{array}{l}\text { Lascas de roca caliza dispuestas en forma horizontal que } \\
\text { modelan paredes rectas correspondientes a una manguera. Las } \\
\text { paredes rectas presentan una altura de 0,70 m y espesores que } \\
\text { van de 0,40 a 0,50 m. }\end{array}$ \\
\hline Est. 06 & $\begin{array}{l}\text { S. } 32^{\circ} 49^{\prime} 53.37^{\prime \prime} \\
0.54^{\circ} 26^{\prime} 46.00^{\prime \prime}\end{array}$ & $\begin{array}{l}\text { Pozo de agua cuya boca es de 4 m de diámetro, con un contorno } \\
\text { en roca canteada de 0,40 m de altura. La estructura se } \\
\text { encuentra relacionada con las Est. 01 y 02. }\end{array}$ \\
\hline Est. 07 & $\begin{array}{l}\text { S. } 32^{\circ} 49^{\prime} 50.85^{\prime \prime} \\
0.54^{\circ} 26^{\prime} 53.03^{\prime \prime}\end{array}$ & $\begin{array}{l}\text { Relicto de cercos o manguera construido con lajas cortas (entre } \\
20 \text { y } 40 \mathrm{~cm} \text { ) de roca caliza, dispuestas en forma horizontal y } \\
\text { encastradas unas a otras. }\end{array}$ \\
\hline
\end{tabular}

Tabla 3. Síntesis de las características de las estructuras en piedra relevadas en prospección.

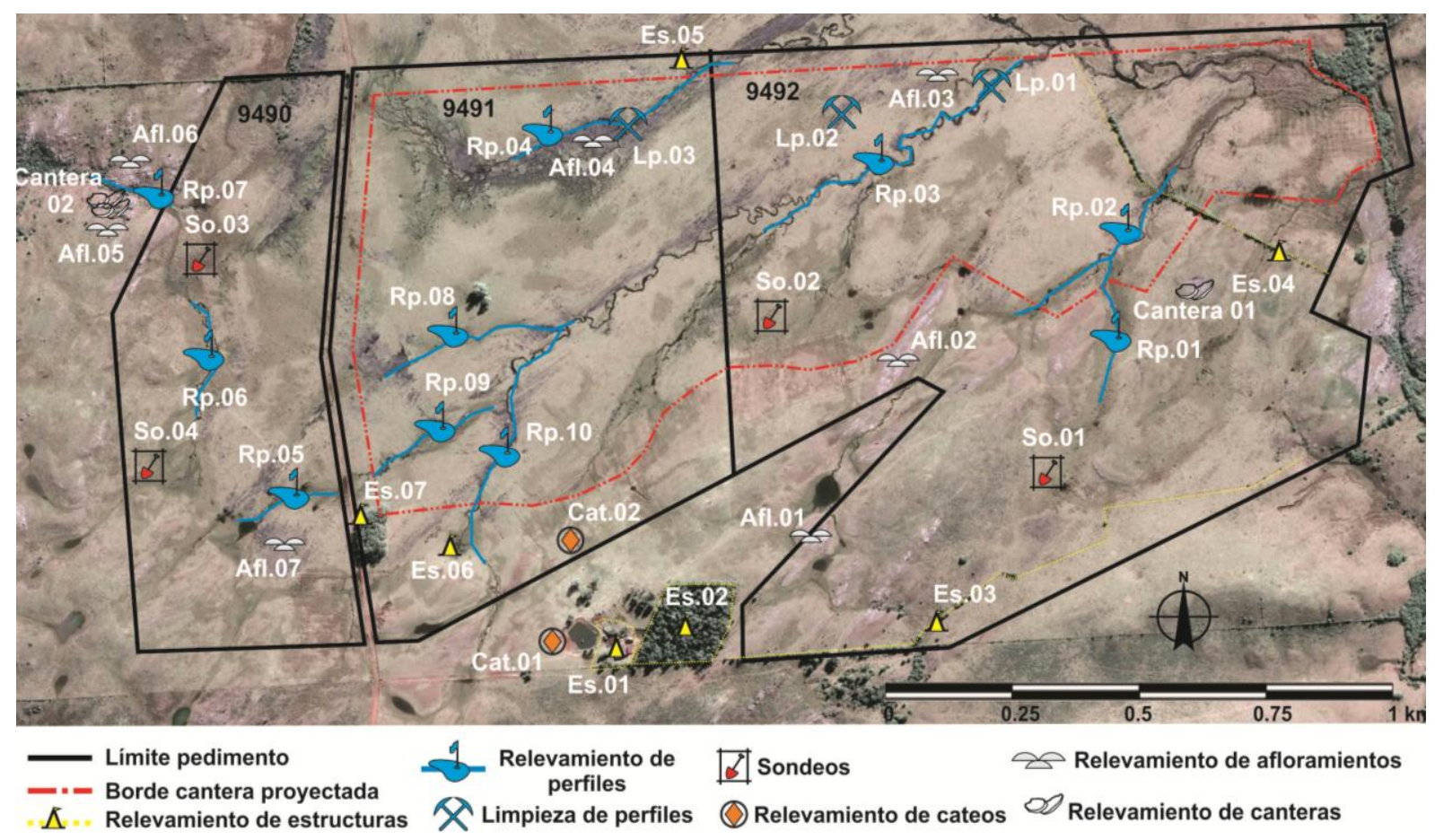

Figura 4. Distribución espacial de intervenciones y ubicación de las estructuras en base a imagen Satelital Google Earth (Fuente: CAPDEPONT y DEL PUERTO, 2014:27). 


\section{Revista de Arqueologia Pública}
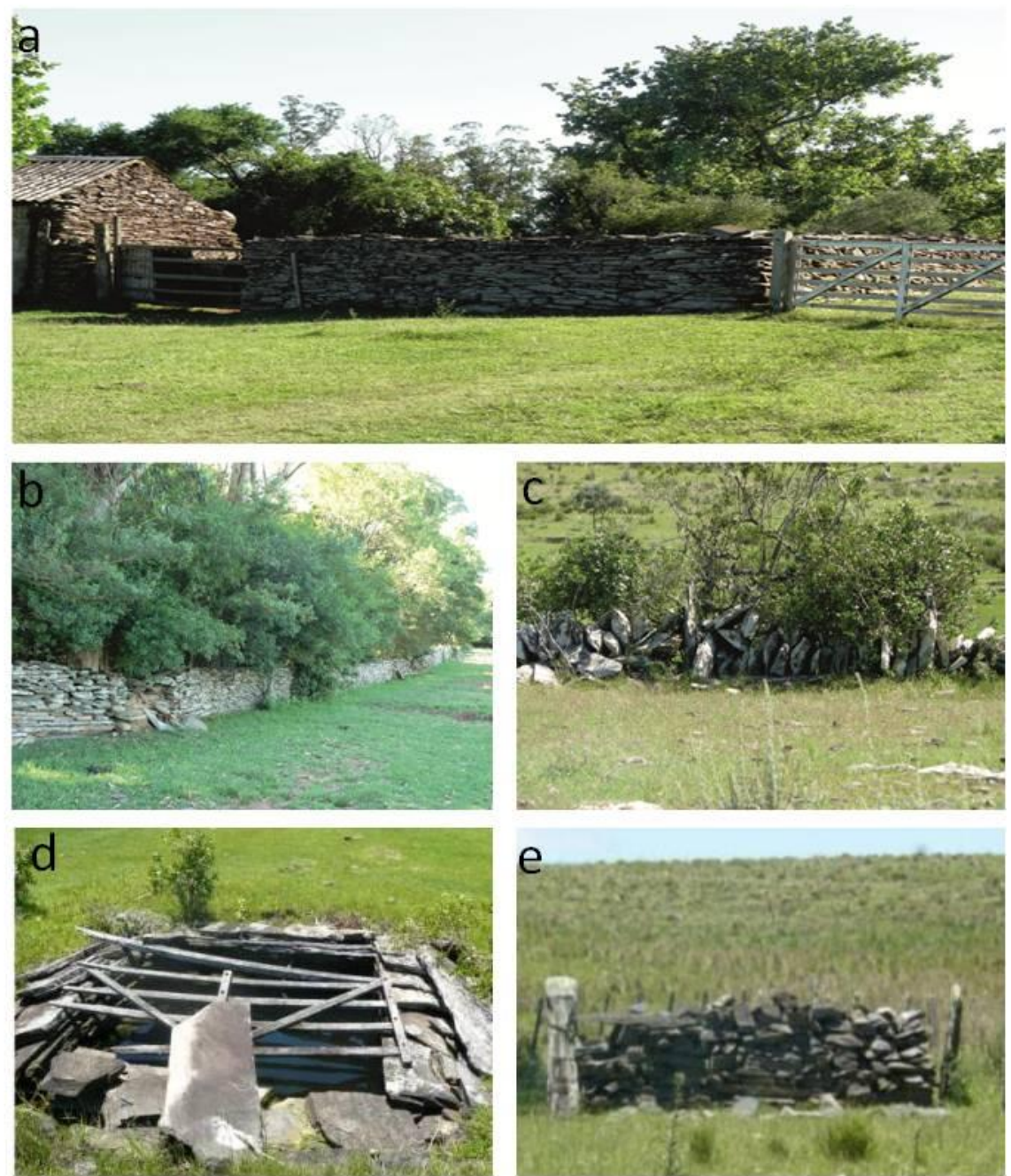

Figura 5. Ejemplo de estructuras en piedra relevadas: a. Est. 01; b. Est. 02; c. Est. 04; d. Est. 06 y e. Est. 07 (Fuente: CAPDEPONT y DEL PUERTO, 2014).

Por último, en este departamento, en el marco de otro proyecto de explotación de roca caliza, se realiza el EIARq en parte de los padrones № 3072, 3184, 5446, 8363. En el área se identificaron afloramientos graníticos y de roca caliza, así como antiguas canteras de extracción de estas rocas. Asociados a estas canteras, fuera del perímetro del pedimento minero, se registró la presencia de dos estructuras en piedra, adjudicadas a hornos de cal (Tabla 4 y Figuras 6). De acuerdo a lo referido por habitantes locales (J. Cabrera entrevistado en 2010 en el marco del EIARq), dichos hornos pertenecían a la familia Jáuregui y el mayor de ellos (Horno 2) habría estado en funcionamiento hasta la década de 1980 (Figura 7). La fabricación de cal, a través de la combustión de rocas calizas, es un proceso cuyo uso se extendió principalmente a partir de principios del siglo 


\section{Revista de Arqueologia Pública}

XVIII. Estos tipos de estructuras también se encuentran en otros departamentos del país, como en Colonia (Calera de las Huérfanas), Soriano (Calera del Dacá) y Maldonado (Hornos de Sierra de Carapé) (e.g. VADELL, 1955; LOCKHART, 1964; FERRES, 1975).

\begin{tabular}{|c|l|l|}
\hline Identificador & Coordenadas & \multicolumn{1}{|c|}{ Características de estructuras } \\
\hline Est.01 & S. $33^{\circ} 1^{\prime} 30.60^{\prime \prime}$ & $\begin{array}{l}\text { La estructura se encuentra fuera del área de pedimento por lo } \\
\text { que no sufrirá impacto. Se encuentra asociada a un conjunto de } \\
\text { canteras y una estructura en piedra. La estructura se } \\
\text { caracterizada como horno de cal con una boca central (Figura } \\
10 a) .\end{array}$ \\
\hline Est.02 & $\begin{array}{l}\text { S. } 54^{\circ} 25^{\prime} 1.53^{\prime \prime} \\
\text { Horno } 2\end{array}$ & $\begin{array}{l}\text { S. } 33^{\circ} 1^{\prime} 27.94^{\circ} 24^{\prime} 57.63^{\prime \prime} \\
\text { Se trata de una estructura en piedra, de forma rectangular, con } \\
\text { altura de 1,30 a 1,50 m, que se identifica como corral (Figura } \\
\text { 10b) en estrecha relación funcional y cronológica con la Est.01 y } \\
\text { las antiguas canteras del entorno. }\end{array}$ \\
\hline
\end{tabular}

Tabla 4. Síntesis de las características de las estructuras en piedra relevadas en actividad de prospección.

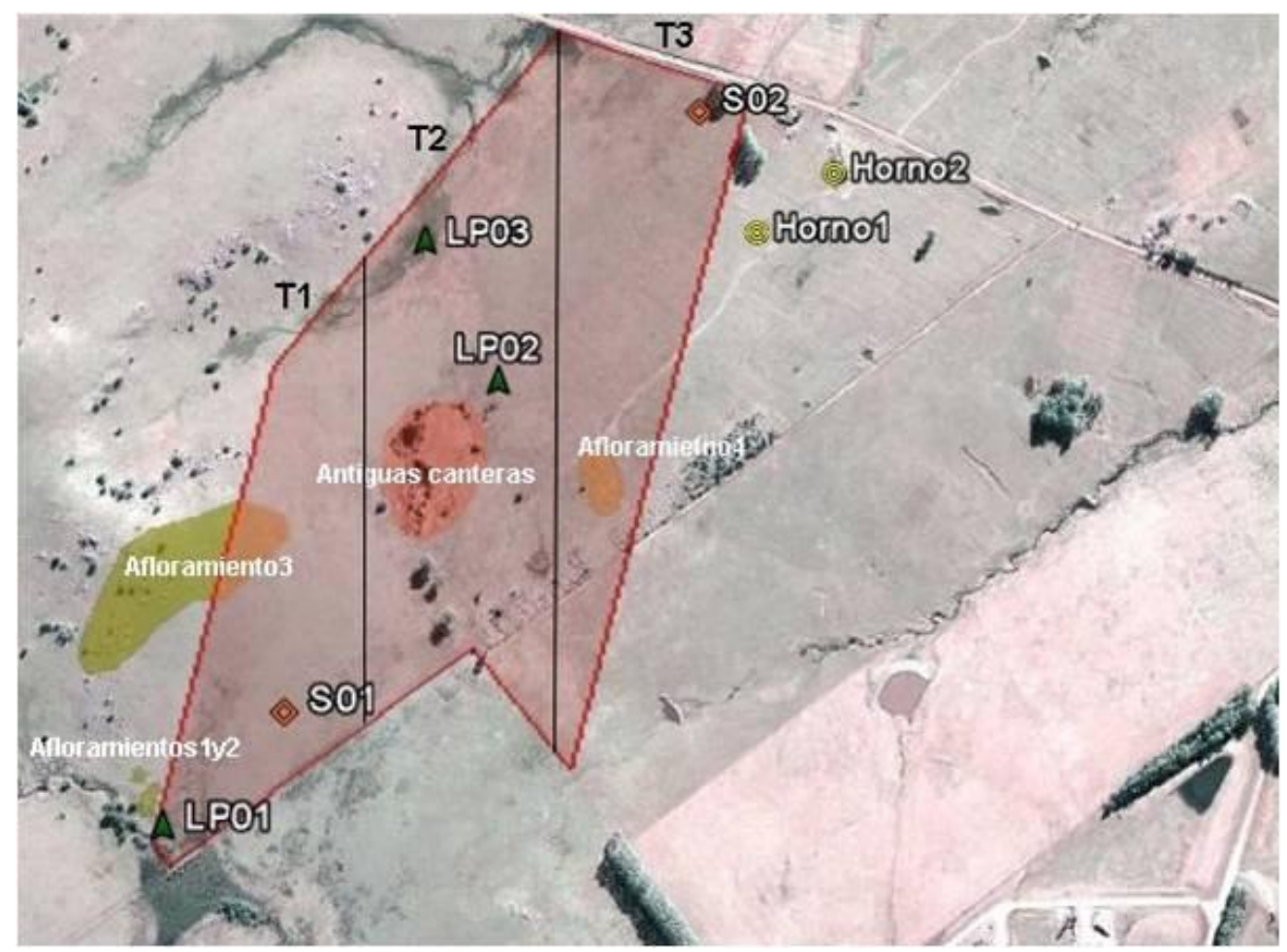

Figura 6. Delimitación del área de obra, ubicación de hornos y actividades realizadas (sondeos SO, Limpieza de perfiles LP) en base a imagen Satelital Google Earth (Fuente: CAPDEPONT y DEL PUERTO, 2010:15). 

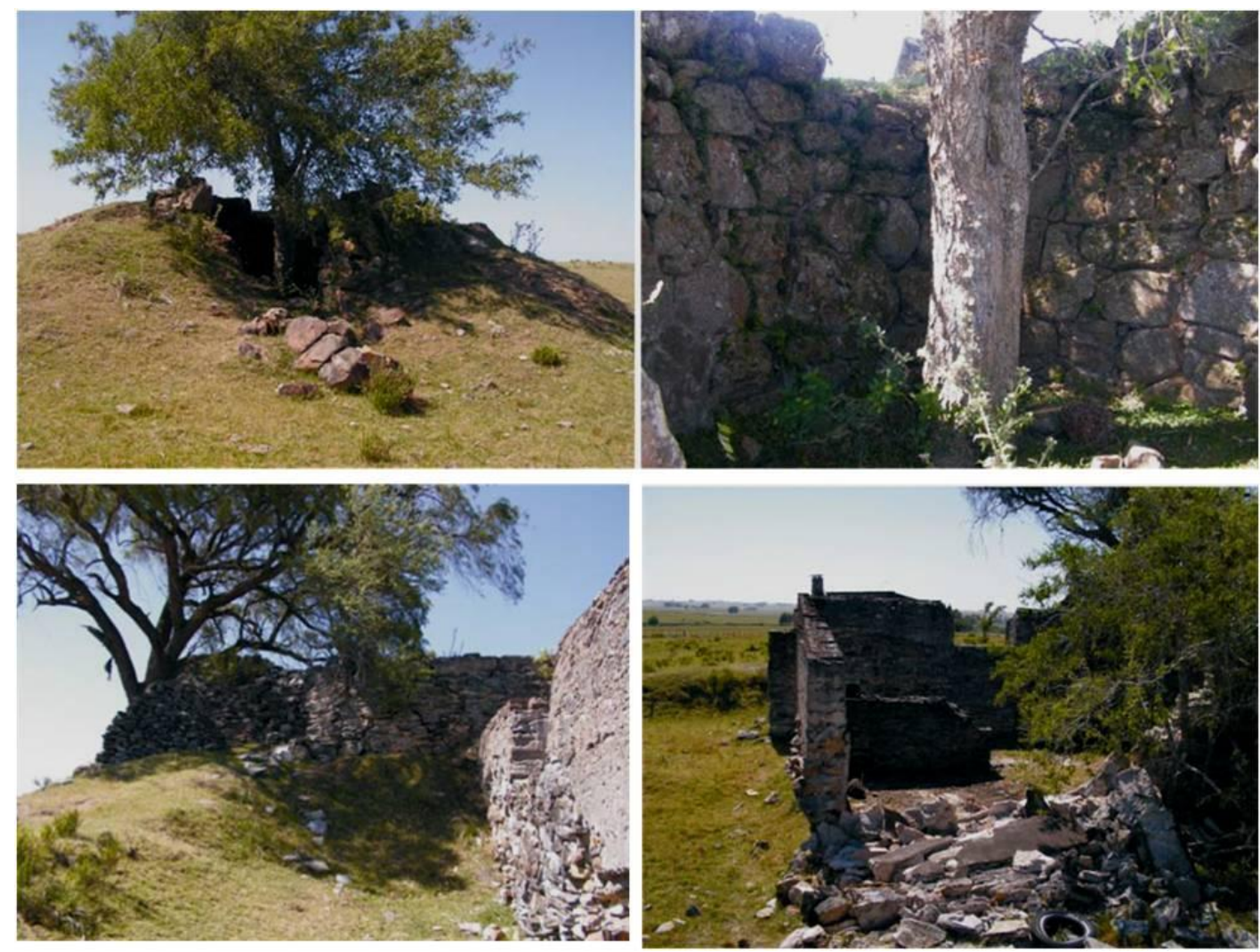

Figura 7. Hornos de Cal relevados: en las imágenes superiores se observan distintas vistas del Horno 1 y en las imágenes inferiores del Horno 2.

Rivera

En parte de los padrones № 2448, 3687, 8625, 8510, 9402, 5331 y 8758 se proyecta un nuevo emprendimiento minero relacionado con la extracción del mineral aurífero. A $5 \mathrm{~km}$ del área de estudio se encuentran las Minas de Zapucay, declaradas Monumento Histórico por la Comisión del Patrimonio Cultural de la Nación (Ministerio de Educación y Cultura). Las mismas funcionaron desde 1890 a 1916, configurando un paisaje de época histórica, relicto del proceso de poblamiento y explotación minera. Asimismo, $15 \mathrm{~km}$ al $\mathrm{NO}$ del área se encuentra un poblado rural, adyacente a la ciudad de Minas de Corrales. Dicho poblado estuvo estrechamente ligado a la explotación de las minas de oro de la zona, que comenzó a funcionar en 1870 (e.g. BARRIOS PINTOS, 1962, 1985; SIMOES et al., 1968). En el EIArq realizado se registraron mangueras, corrales y estructuras de vivienda construidas con rocas del lugar (Figura 8, Figura 9 y Tabla 6). Estos vestigios materiales, darían cuenta del emprendimiento minero de la Compañía de Minas de Oro del Río de la Plata a quienes 


\section{Revista de Arqueologia Pública}

se les adjudica la primera explotación de la mina de Zapucay. De acuerdo a las características y datos históricos, las estructuras relevadas tendría una cronología comprendida entre 1830 y postrimerías del siglo XX. La antigüedad máxima, se sustentaría en las evidencias del proceso de dominación histórica del área, en tanto que la antigüedad mínima, estaría marcada por la entrada en desuso del cercado de piedra (NAHUM, 1997).

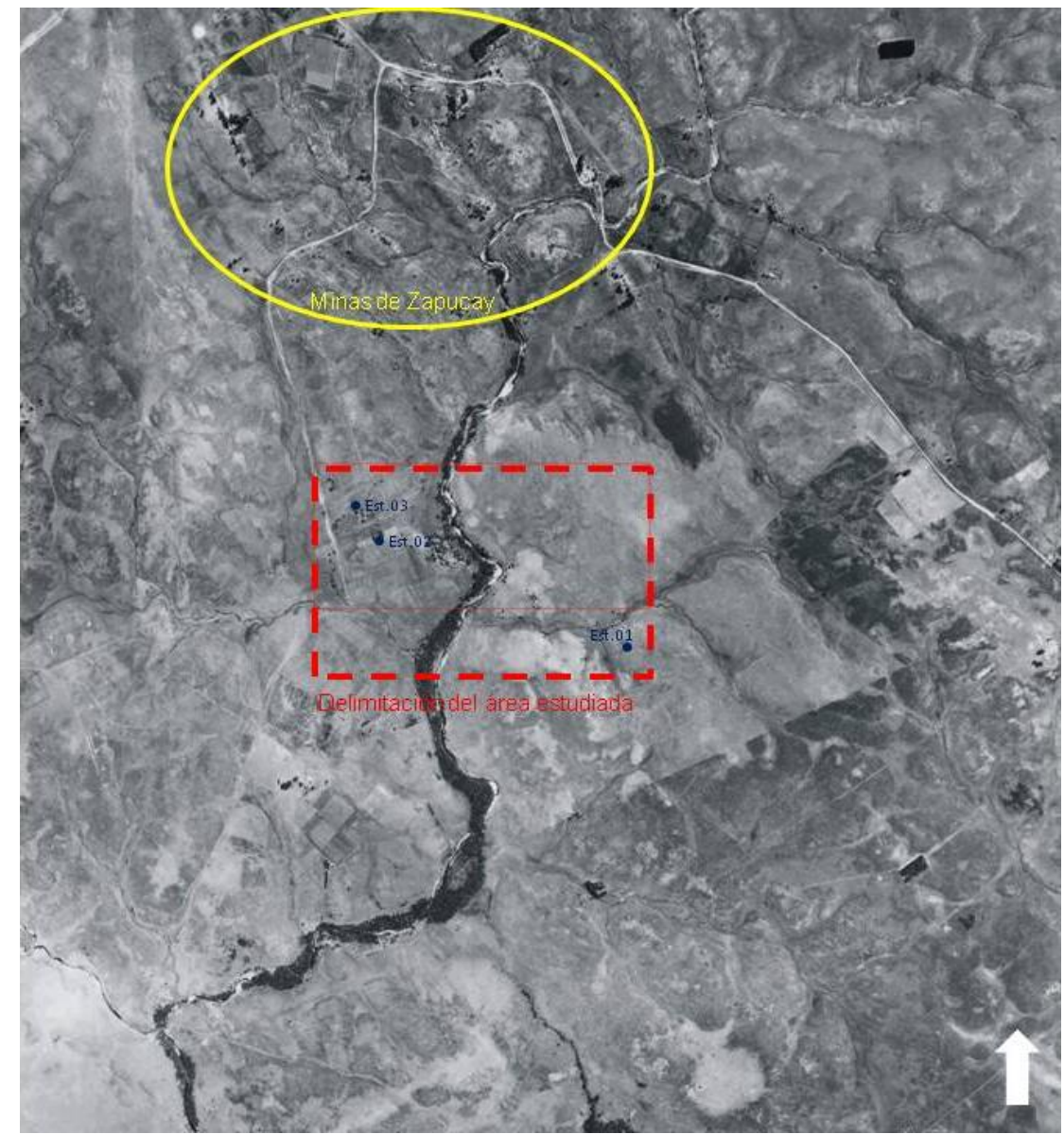

Figura 8. Foto área 220-071 del Servicio Geográfico Militar donde se delimita en rectángulo rojo el área del emprendimiento y en circulo amarillo las antiguas áreas de explotación minera (Modificado de CASTIÑEIRA et al., 2006).

\begin{tabular}{|c|c|l|}
\hline Identificador & Coordenadas & \multicolumn{1}{c|}{ Características de estructuras } \\
\hline Est. 01 & $\begin{array}{c}\text { S. } 31^{\circ} 40^{\prime} 43.64 " \\
0.55^{\circ} 18^{\prime} 41.31^{\prime \prime}\end{array}$ & $\begin{array}{l}\text { Estructura en piedra construida con roca granítica canteada. } \\
\text { Dicha estructura se extiende por 400 m. La manguera resaltar el } \\
\text { límite natural que impone la presencia de una cañada tributaria } \\
\text { del Ao Zapucay. }\end{array}$ \\
\hline Est. 02 & $\begin{array}{l}\text { S. } 31^{\circ} 40^{\prime} 30.09^{\prime \prime} \\
0.55^{\circ} 19^{\prime} 9.58^{\prime \prime}\end{array}$ & $\begin{array}{l}\text { Estructura en piedra de forma circular correspondiente a un } \\
\text { corral construido con roca granítica. Presenta un diámetro de 50 }\end{array}$ \\
\hline
\end{tabular}


Revista de Arqueologia Pública

\begin{tabular}{|c|l|l|}
\hline & & $\mathrm{m}$, altura de 1,15m y un espesor de 0,70 m. \\
\hline \multirow{2}{*}{ Est. 03 } & $\begin{array}{l}\mathrm{S} .31^{\circ} 40^{\prime} 28.12 " \\
0.55^{\circ} 19^{\prime} 12.04 "\end{array}$ & $\begin{array}{l}\text { La estructura corresponde a una construcción de vivienda con } \\
\text { paredes de ladrillo y roca canteada, así como un pozo de agua. } \\
\text { La vivienda se encuentra en estrecha relación funcional y } \\
\text { cronológica con el resto de las estructuras del área. }\end{array}$ \\
\hline
\end{tabular}

Tabla 6. Síntesis de las características de las estructuras en piedra relevadas en actividad de prospección.
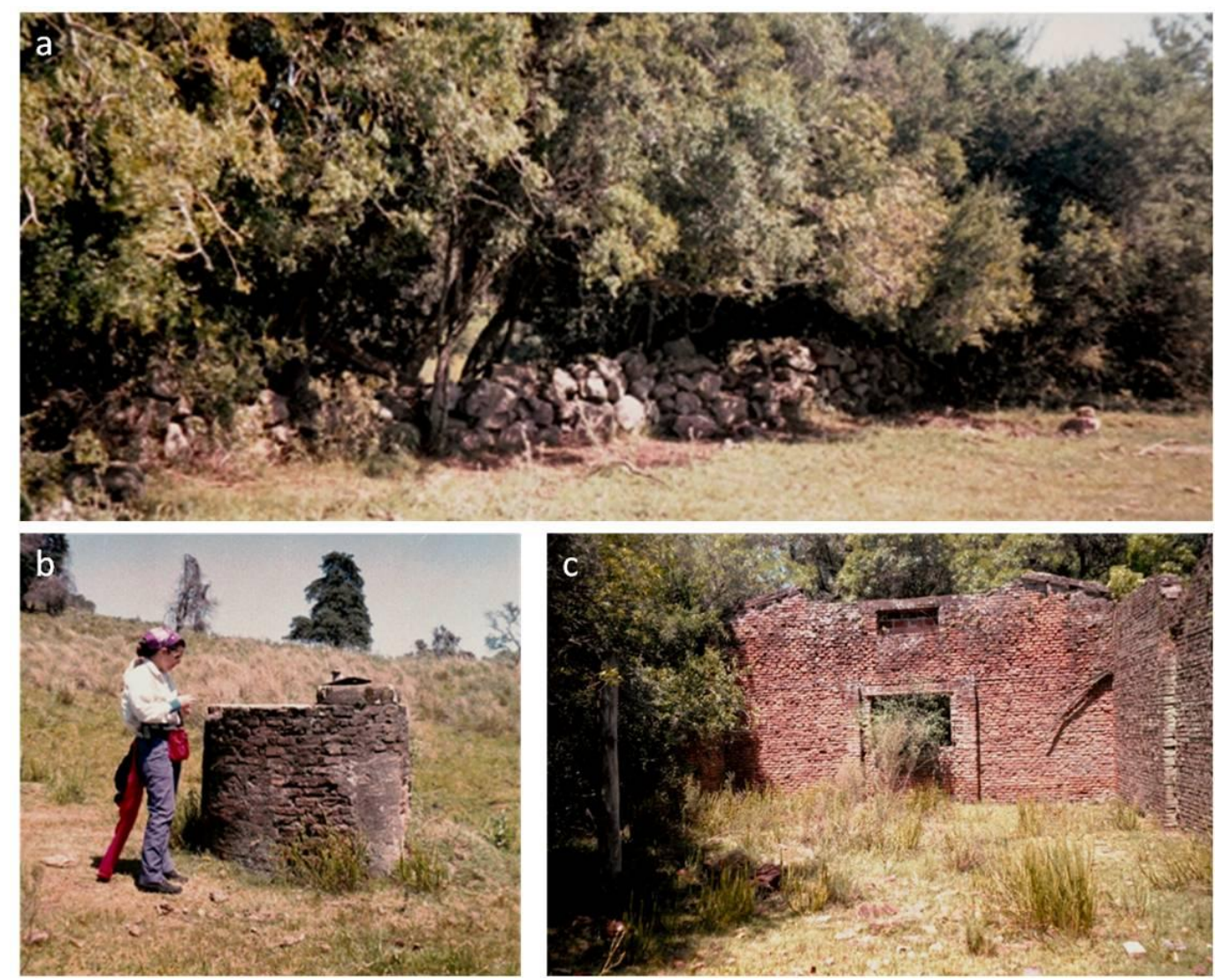

Figura 9. Estructuras en piedra relevadas en el área: a. corral de roca granítica; b. pozo de agua construido con roca granítica y ladrillo y c. relicto de estructura de vivienda construida en ladrillo.

\section{Artigas}

Algunos sectores del departamento de Artigas, a nivel arqueológico general, se caracterizan por la presencia de registro material de los primeros pobladores del territorio. En términos generales, el área de estudio se enmarca en una zona de gran relevancia arqueológica, reconocida desde los inicios de la arqueología nacional (e.g. BÓRMIDA, 


\section{Revista de Arqueologia Pública}

1964, 1964a; CAMPÁ, 1962; CAMPÁ y VIDART, 1962; TADDEI, 1980, 1980a; VIDART, 1962). Los sitios prehistóricos más característicos presentan restos de industria lítica adjudicada al denominado "complejo cultural catalanense" (HILBERT, 1991; SANTOS, 1967; TADDEI, 1980b, entre otros) adjudicados por TADDEI (1987) a sitios Cantera-Taller. Los sitios se asocian a los afloramientos de metacuarcita, siendo la arenisca silicificada la fuente principal en la elaboración de los instrumentos líticos relevados en el área. La región también fue ocupada durante períodos prolongados por diferentes culturas a lo largo del tiempo, tal como lo han expresado TADDEI (1964), HILBERT (1991) y AUSTRAL (1995), entre otros.

Las dos áreas de estudio que se expondrán a continuación presentan suelos perturbados, producto de explotaciones mineras. El ecosistema básico corresponde a praderas naturales, sobre suelos superficiales no inundables, rocosos y pedregosos. La región morfoestructural, donde se emplazan ambos emprendimientos, es conocida como Cuesta Basáltica (BOSSI et al., 1998). La geología del área, producto de diferentes niveles de coladas basalitas, ha generado desde la década de 1950, extracciones de minerales que impactaron estos paisajes. El estudio de impacto realizado sobre un área de 11 Hás, que afecta un sector del padrón № 5375, aportó evidencias del paisaje cultural histórico representado por dos estructuras en piedra (Figura 10, Figura 11 y Tabla 7). 


\section{Revista de Arqueologia Pública}

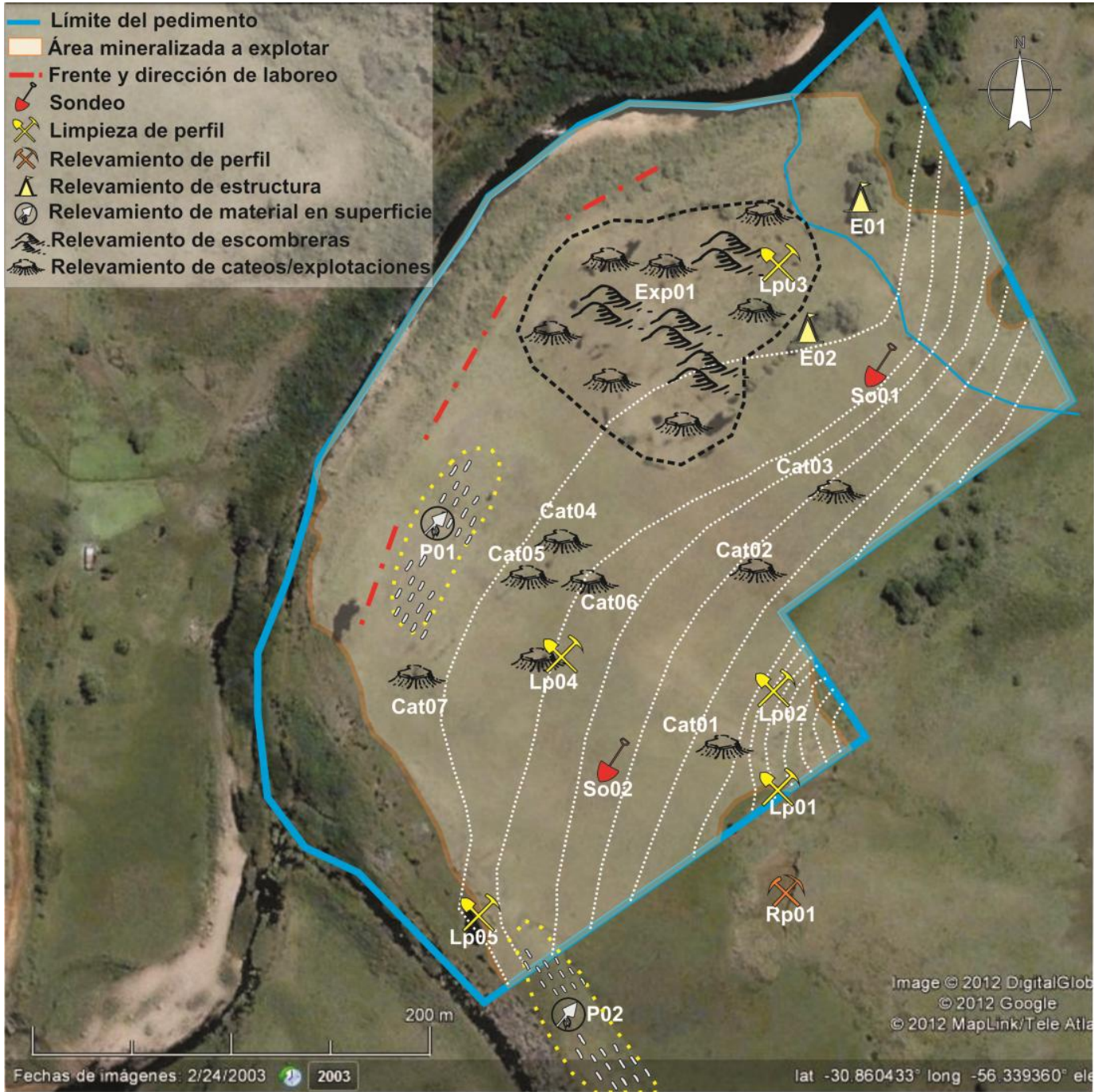

Figura 10. Distribución espacial de intervenciones y ubicación de las estructuras en base a imagen Satelital Google Earth (Fuente: DEL PUERTO y CAPDEPONT, 2012:24)

\begin{tabular}{|c|c|l|}
\hline Identificador & Coordenadas & \multicolumn{1}{|c|}{ Características de estructuras en cota 150-300m } \\
\hline Est. 01 & $\begin{array}{l}\text { S. } 30^{\circ} 51^{\prime} 31.88^{\prime \prime} \\
\text { O.56²'24.12" }\end{array}$ & $\begin{array}{l}\text { Restos de una construcción cuadrangular de unos } 10 \mathrm{~m}^{2} . \\
\text { Presenta tres paredes de piedra de 1 m de altura. De acuerdo a } \\
\text { informantes locales los restos pertenecieron a una antigua posta } \\
\text { de diligencia. }\end{array}$ \\
\hline Est. 02 & S. $30^{\circ} 51^{\prime} 31.88^{\prime \prime}$ & $\begin{array}{l}\text { Alineamiento de piedras de escaso desarrollo vertical y } 50 \mathrm{~m} \text { de } \\
\text { extensión. Integrada mayoritariamente por geodas } \\
\text { fragmentadas. La estructura corresponde a antiguas filas de } \\
\text { clasificación de geodas. }\end{array}$ \\
\hline
\end{tabular}

Tabla7. Síntesis de las características de las estructuras en piedra relevadas en actividad de 


\section{ARTIGO}

\section{Revista de Arqueologia Pública}
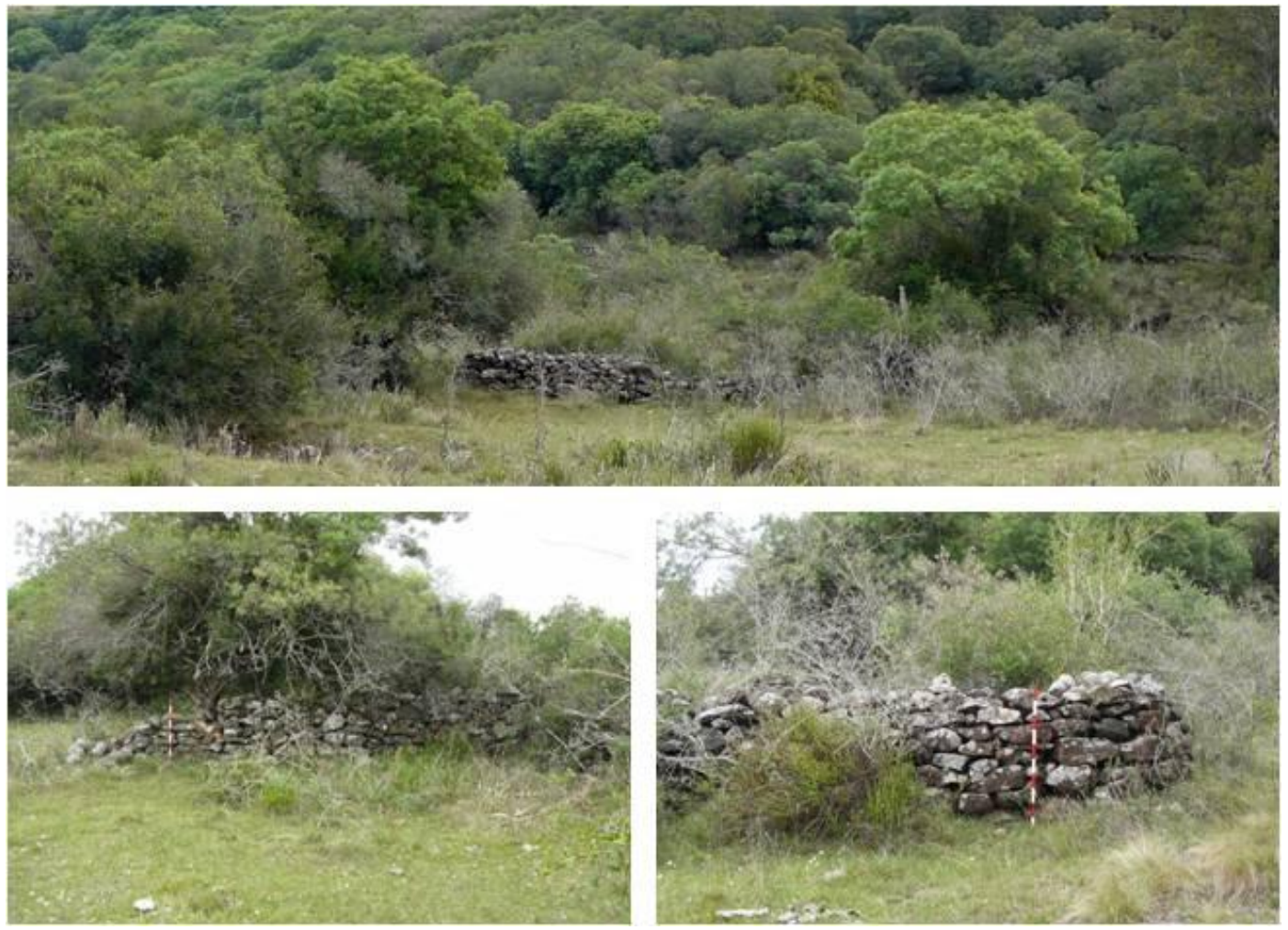

Figura 11. Relicto de la estructura en piedra adjudicada a una antigua posta de diligencia.

\section{Consideraciones finales}

Las actividades de prospección, realizadas en el marco de los EIArq, permitieron caracterizar diferentes tipos de estructuras en piedra construidas con roca local canteada. Estas estructuras evidencian los procesos de ocupación y explotación del medio rural desde el siglo XVII hasta la actualidad. Estos elementos materiales manifiestan un paisajes en continúa construcción y modificación. Los mismos son testimonio de la formación del paisaje rural y la configuración de prácticas económicas y productivas, sociales y simbólicas. Las estructuras relevadas se vinculan a la explotación pecuaria del siglo XVII, evidenciando prácticas sociales afirmadas en un sistema tradicional de uso de la tierra.

El cercamiento de los campo, mediante cercos o mangueras de piedra, se dio con mayor intensificación hacia el siglo XVIII, posibilitando el ejercicio pleno de la propiedad de la tierra, sumado al control del ganado. La explotación del ganado requirió que el mismo estuviera en áreas limitadas para su mejor manejo y control. El cerco de piedra paso a cumplir esa función, además de delimitar la tierra que cada uno poseía. Ello refleja la

\begin{tabular}{|l|l|l|l|l|l|l|}
\hline (C) Rev. Arqueologia Pública & Campinas, SP & v. 10 & n. 2 & p. 29-51 & JUN. 2016 & ISSN 2237-8294 \\
\hline
\end{tabular}




\section{Revista de Arqueologia Pública}

estructura de la propiedad privada existente en el territorio desde el siglo XVIII (NAHUM, 1997). La práctica de este tipo de cercado cayó en desuso hacia fines del 1800 con el advenimiento del alambre.

Muchas de las estructuras en piedra, principalmente mangueras y corrales en buen estado de conservación y grandes dimensiones, se encuentran mapeadas y referidas en la cartográfica topográfica del Servicio Geográfico Militar. No obstante, las estructuras registradas y presentadas en este trabajo, no se observan en la mencionada cartografía. Los tipos de estructuras relevadas son la huella material del inicio del desarrollo económico del país, esencialmente pecuarios. Para las mismas se reconocen distintos uso, como ser corrales para encerrar ganado, mangueras de delimitación de espacios, estructuras con fines habitacionales o como recinto de paso de diligencia. La construcción de éstas se basa en el sistema de levantamiento de muros denominado de piedra seca. Este sistema constructivo consiste en la elevación del muro mediante la superposición y/o encastre de bloques o lajas de roca, sin ningún tipo de argamasa o aglutinante para fijarlas (sensu AGUIRRE, 1993). Se considera que gran parte de los corrales y mangueras habrían sido construidos con mano de obra esclava, tanto indígena como africana.

El transporte por el territorio, escasamente poblado para el siglo XVIII, se realizaba principalmente en carretas. A este medio de transporte se sumaban los servicios de postas, permitiendo la comunicación entre los centros poblados del territorio, cambio de caballos, servicio de fonda y alojamiento entre otros (ARREDONDO, 1958). Los restos de lo que habría sido un posta de diligencia, relevados en el departamento de Artigas, son evidencia material histórica de la movilidad por el territorio en tiempos históricos.

Dentro del período adjudicado a las estructuras mencionadas en párrafos anteriores, se encuentran también los hornos de cal registrados en el departamento de Treinta y Tres. Actualmente, el departamento es un importante polo minero-industrial, vinculado con la producción calera-cementera. Ello se debe a la existencia de zonas muy ricas en yacimientos calcáreos, en un entorno de tierras de bajo índice de productividad agropecuaria. En estas zonas se encuentran por lo general estructuras relacionadas con la producción de cal, como las expuestas en este trabajo. La fabricación de cal, a través de la combustión de rocas calizas, es un proceso cuyo uso se extendió principalmente en la construcción de muros de cal y canto, a partir de principios del siglo XVIII en el territorio. En cuanto a la explotación, John Mawe, hacia 1800, relata: "Se separa la piedra de cal por medio de cuña y palancas y se transporta en grandes piezas a los hornos, donde se rompe 


\section{Revista de Arqueologia Pública}

en fragmentos de forma conveniente y se quema con madera. Los hornos son espaciosos, pero tan mal construidos que el proceso de calcinación es lento y cansados. Cuando la cal está apagada, se mide, se pone en bolsas hechas de cuero fresco y se envía en grandes carretas tiradas por bueyes..." (BARRIOS PINTOS, 1969:346). Generalmente los hornos están ubicados cercanos a los montes, ya que el matorral y la retama que se encortaba en los mismos, era el combustible utilizado. La leña se introducía por la boca del horno hasta el hueco central. Allí se encendía el fuego que iba ganando temperatura suavemente. De esta forma las calizas comenzaban a sudar, perdiendo lentamente la humedad. Una hornada de cal insumía aproximadamente 150 carretas de leñan (SALA DE TOURON et al., 1967), lo que lleva a considerar un rotundo cambio en el paisaje circundante de estos hornos.

Las evidencias materiales del siglo XVIII forman parte del patrimonio histórico del territorio y evidencian las modificaciones que se han dado en el paisaje rural. Modificaciones relacionadas con la tala de monte para obtención de madera y extracción de rocas para la construcción de estructuras. Los actuales emprendimientos económicos también habrían generado una alteración significativa sobre estas evidencias patrimoniales si no fueran consideradas las áreas de exclusión propuestas. Se considera que los estudios realizados lograron un equilibrio ente los intereses económicos y la conservación de la memoria cultural mediante la implementación de medidas de protección para las estructuras en piedra y la puesta en conocimiento de su ubicación, características y valor cultural. Considerando que el conocimiento generado en estos proyectos de EIArq es de carácter público y relevante, se realizó en esta instancia la difusión de algunos de los datos obtenidos en los estudios de impacto, que de otra manera permanecerían archivados en expedientes públicos y oficinas privadas.

\section{Bibliografía}

AGUIRRE, Antxón. "La Piedra seca em Vasconia". Revista de Tradiciones Populares No 38, Vol. 1:925-951, Albacete. 1993.

AMADO, Xuxo y BARREIRO, David. La gestión del impacto y la prospección arqueológica. Laboratorio de Arqueoloxía, Instituto de Estudios Galegos - Padre Sarmiento, CSIC-Xunta de Galicia. 2007.

AMADO, Xuxo; BARREIRO, David; CRIADO, Felipe y MARTÍNEZ, María. "Especificaciones para una gestión del Impacto desde la Arqueología del Paisaje". TAPA 26, Santiago de Compostela, 2002. 


\section{Revista de Arqueologia Pública}

ARREDONDO, Horacio. "El transporte a sangre en el antiguo Montevideo y su extensión al interior" Anales Históricos de Montevideo, Concejo Departamental de Mont., Mont., p. 208. 1958.

AUSTRAL, Antonio. Los Cazadores del Sitio Estratificado Pay Paso hace 10.000 años. En: M. Consens, J. López Mazz y C. Curbelo (Eds.), Arqueología en el Uruguay, pp. 212-218, Montevideo. 1995.

BARREIRO, David. "Un modelo de estudio de impacto arqueológico". En I Congreso de ingeniería civil, territorio y medio ambiente, pp. 481-491. Madrid. 2002

BARRÁN, José Pedro. "Historia Uruguaya. Apogeo y Crisis del Uruguay Pastoril y Caudillesco" Tomo 4, 1838-1875. Ediciones de la Banda Oriental, Montevideo. 1974.

BARRIOS PINTO, Aníbal. De las vaquerías al alambrado: contribución a la historia rural uruguaya. Biblioteca Uruguaya, Vol. 5. Editorial Nuevo Mundo. Montevideo. 1967

BARRIOS PINTO, Aníbal. Viajeros cronistas de la Tierra Purpúrea. Montevideo. 1969.

BARRIOS PINTO, Aníbal. Rivera en el Ayer, Ed. Minas, Minas. 1962

BARRIOS PINTO, Aníbal. Rivera una historia diferente. Intendencia Municipal de Rivera, Rivera. 1985

BARRIOS PINTO, Aníbal. Historia de la Ganadería en el Uruguay 1574-1971. Talleres Gráficos Comunidad del Sur, Montevideo.1973.

BÓRMIDA, Marcelo. "Las Industrias Líticas Precerámicas del Arroyo Catalán Chico y Río Cuareim (Artigas)". Revista di Scienze Prehistoriche, 19 (1-4): 195- 232, Florencia. 1964. BÓRMIDA, Marcelo. "El Cuareimense. Una Antigua Industria Lítica del Norte de Uruguay”. Homenaje a Fernando Márquez Miranda: 105-131, Madrid. 1964a.

BOSSI, Jorge; FERRANDO, Lorenzo; MONTAÑA, Jorge; CAMPAL, Néstor; MORALES, Héctor; GANCIO, Fernando; SCHIPILOV, Alejandro; PIÑEYRO, Daniel y Peter SPRECHMAN. GEOCARTA. Carta geológica del Uruguay 1:500.000. Versión 1.01. Geoeditores S.R.L., Montevideo. 1998.

CAMPÁ, Raúl. "La Industria Lítica más Antigua de América del Sur” Amerindia 1:107-113, Montevideo. 1962.

CAMPÁ, Raul y VIDART, Daniel. "El Catalanense. Una Industria de Morfología Protolítica en el Uruguay". Amerindia 1: 87-100, Montevideo. 1962.

CABRERA PÉREZ, Leonel y Oscar MAROZZI. "Sitio PR14D01, Río Tacuarí, Depto. de Treinta y Tres". En Arqueología uruguaya, hacia el fin del milenio. Tomo I: 69-81, Gráficos del sur, Montevideo, 2001. 


\section{Revista de Arqueologia Pública}

CAPDEPONT, Irina y DEL PUERTO, Laura. Diagnostico del estudio y evaluación de impacto arqueológico. Departamento de Treinta y Tres. pp. 1-24. CPCN, Ministerio de Educación y Cultura. 2010.

CAPDEPONT, Irina y DEL PUERTO, Laura. Informes EIARq en el Departamento de Treinta y Tres. pp. 1-65. CPCN, Ministerio de Educación y Cultura. 2013.

CAPDEPONT, Irina y DEL PUERTO, Laura. EIARq del Departamento de Treinta y Tres. pp. 1-60. CPCN, Ministerio de Educación y Cultura. 2014

CAPDEPONT, Irina; DEL PUERTO, Laura y Hugo INDA. Informe EIARq del Departamento de Treinta y Tres. Exp CPCN № 475/04. Montevideo, 2004.

CASTIÑEIRA, Carola; CAPDEPONT, Irina y DEL PUERTO, Laura. Informe Técnico del Departamento de Rivera. pp. 1-21. CPCN, Ministerio de Educación y Cultura. 2006

CRIADO, Felipe; VILLOCH, Victoria y BARREIRO, David. "Arqueología y Parques Eólicos en Galicia: Proyecto Marco de Evaluación de Impacto" CAPA № 5. Santiago de Compostela, 2000.

FERRES, Carlos. La Compañía de Jesús en Montevideo. Montevideo. 1975.

DEL PUERTO, Laura y CAPDEPOTN, Irina. Informe de Evaluación Arqueológica del Departamento de Artigas. pp. 1-54. CPCN, Ministerio de Educación y Cultura. 2012.

FEMENÍAS, Jorge. "Amontonamientos artificiales de piedras en cerros y elevaciones de nuestro territorio". Revista Antropológica 1(1):13-16. 1983.

FLORINES, Andrés, GEYMONAT, Jacqueline y TOSCANO, Arturo. Informe arqueológico e histórico del cerco de piedra seca del complejo de parques eólicos "Emanuelle Cambilargiú" Sierra de los Caracoles (Maldonado), pp. 1-33. CPCN, Ministerio de Educación y Cultura. 2011.

HILBERT, Klaus. Aspectos de la Arqueología en el Uruguay, Verlang Phillip Von Zabern, Maiz aim rheim. 1991.

LOCKHART, Washington. "Las ruinas del Dacá". Revista Histórica de Soriano, Soriano, 10:32-36. 1964.

MGAP-MINISTERIO DE GANADERÍA, AGRICULTURA Y PESCA. Compendio Actualizado de Información de Suelos del Uruguay, División de Suelos y Agua. MGAP, Montevideo, Uruguay. (Programa y Base de Datos en formato CD) 2001.

NAHUM, Benjamín. Manual de Historia Uruguaya. 2 tomos. EBO, Montevideo.1997

PRIETO, Oscar; ÁlVAREZ, A.; ARBENOZI, G.; DE lOS SANTOS J.A. y A. VESIDI. "Arqueología del Departamento de Treinta y Tres". En: Colección Los Departamentos. Nuestra Tierra, № 4:20-25, Montevideo. 1970. 


\section{Revista de Arqueologia Pública}

SALA DE TOURON, Lucía, DE LA TORRE, Nelson y RODRÍGUEZ, Julio. Estructura económico-social de la Colonia. 1967. Editorial Pueblos Unidos, Montevideo.

SANTOS, Omar. "El gran Yacimiento Paleolítico del Dpto. de Artigas - Arroyo Catalán Chico" Boletín 1:3-10. Centro de Arqueología de Rivera. 1965.

SIMOES, Lilión; CAIRELLO, Julio; PEREYRA, Arturo y TITO, Mario (Coordinadores)

"Rivera". En Colección Los Departamentos, № 3, Ed. Nuestra Tierra, Montevideo. 1968.

TADDEl, Antonio. "Un yacimiento Precerámico en el Uruguay". Baessier - Archiv. Nene Folge Band, 12:317-372. Verlag Von Dietrich Reimer. Berlín. 1964.

TADDEI, Antonio. "Industrias Líticas del Uruguay y su Relación con la Pampa-Patagonia de Argentina". Revista de Arqueología, 19:58-64. Madrid. 1980.

TADDEl, Antonio. "Industrias Líricas del Uruguay y su relación con la Pampa-Patagonia de Argentina". Revista de Arqueología, 21:24-31. Madrid. 1980a.

TADDEI, Antonio. "Carácter y Contenido de Algunas Industrias Precerámicas del Territorio Uruguayo". Sapiens (4):81-99. Chivilcoy. 1980b.

TADDEI, Antonio. "Algunos aspectos de la Arqueología Prehistórica del Uruguay". En: Estudios Atacameños. Investigaciones paleoindias al sur de la línea ecuatorial. $\mathbf{N}$ ㅇ 8:62-93.Universidad del Norte Editor, San Pedro de Atacama. Chile. 1987

VADELL, Abel Natalio. Antecedentes Históricos del antiguo puerto de las Vacas (EI Carmelo), del extinguido pueblo de Las Viboras y de la Calera de las Huérfanas. Tall. Graf. Optimus, Buenos Aires. 1955.

VIDART, Daniel. "Los Estratos Culturales del Uruguay Indígena". Amerindia 1:101-106, Montevideo. 1962. 